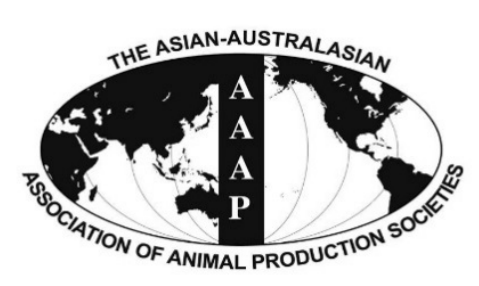

\title{
Genetic Parameters of Pre-adjusted Body Weight Growth and Ultrasound Measures of Body Tissue Development in Three Seedstock Pig Breed Populations in Korea
}

\author{
Yun Ho Choy*, Alam Mahboob, Chung Il Cho, Jae Gwan Choi, Im Soo Choi', \\ Tae Jeong Choi, Kwang Hyun Cho, and Byoung Ho Park \\ Animal Breeding and Genetics Division, National Institute of Animal Science, Chonan 330-801, Korea
}

\begin{abstract}
The objective of this study was to compare the effects of body weight growth adjustment methods on genetic parameters of body growth and tissue among three pig breeds. Data collected on 101,820 Landrace, 281,411 Yorkshire, and 78,068 Duroc pigs, born in Korean swine breeder farms since 2000, were analyzed. Records included body weights on test day and amplitude (A)-mode ultrasound carcass measures of backfat thickness (BF), eye muscle area (EMA), and retail cut percentage (RCP). Days to $90 \mathrm{~kg}$ body weight (DAYS90), through an adjustment of the age based on the body weight at the test day, were obtained. Ultrasound measures were also pre-adjusted (ABF, EMA, AEMA, ARCP) based on their test day measures. The (co)variance components were obtained with 3 multi-trait animal models using the REMLF90 software package. Model I included DAYS90 and ultrasound traits, whereas model II and III accounted DAYS90 and pre-adjusted ultrasound traits. Fixed factors were sex (sex) and contemporary groups (herd-year-month of birth) for all traits among the models. Additionally, model I and II considered a linear covariate of final weight on the ultrasound measure traits. Heritability $\left(\mathrm{h}^{2}\right)$ estimates for DAYS90, BF, EMA, and RCP ranged from 0.36 to $0.42,0.34$ to $0.43,0.20$ to 0.22 , and 0.39 to 0.45 , respectively, among the models. The $\mathrm{h}^{2}$ estimates of DAYS90 from model II and III were also somewhat similar. The $\mathrm{h}^{2}$ for $\mathrm{ABF}, \mathrm{AEMA}$, and ARCP were 0.35 to $0.44,0.20$ to 0.25 , and 0.41 to 0.46 , respectively. Our heritability estimates varied mostly among the breeds. The genetic correlations $\left(\mathrm{r}_{\mathrm{G}}\right)$ were moderately negative between DAYS90 and BF $(-0.29$ to -0.38$)$, and between DAYS90 and EMA ( -0.16 to -0.26$)$. BF had strong $\mathrm{r}_{\mathrm{G}}$ with RCP $(-0.87$ to -0.93$)$. Moderately positive $\mathrm{r}_{\mathrm{G}}$ existed between DAYS90 and RCP ( 0.20 to 0.28$)$ and between EMA and RCP ( 0.35 to 0.44$)$ among the breeds. For DAYS90, model II and III, its correlations with ABF, AEMA, and ARCP were mostly low or negligible except the $\mathrm{r}_{\mathrm{G}}$ between DAYS90 and AEMA from model III (0.27 to 0.30$)$. The rG between AEMA and ABF and between AEMA and ARCP were moderate but with negative and positive signs, respectively; also reflected influence of pre-adjustments. However, the $\mathrm{rG}_{\mathrm{G}}$ between BF and RCP remained non-influential to trait pre-adjustments or covariable fits. Therefore, we conclude that ultrasound measures taken at a body weight of about $90 \mathrm{~kg}$ as the test final should be adjusted for body weight growth. Our adjustment formulas, particularly those for BF and EMA, should be revised further to accommodate the added variation due to different performance testing endpoints with regard to differential growth in body composition. (Key Words: Pig, Growth Trait, Ultrasound Measures, Heritability, Genetic Correlation)
\end{abstract}

\section{INTRODUCTION}

The current pig performance-testing program in Korea is operated by individual farm owners. The major focuses of testing are body weight at about $90 \mathrm{~kg}$, which represents

\footnotetext{
* Corresponding Author: Yun Ho Choy. Tel: +82-41-580-3354, Fax: +82-41-582-1248, E-mail: ychoy000@korea.kr

${ }^{1}$ Korea Animal Improvement Association, Seoul 137-811, Korea. Submitted Dec. 29, 2014; Revised Mar. 24, 2015; Accepted May 19, 2015
}

growth rate from birth after it is converted to days required to reach $90 \mathrm{~kg}$ body weight, and ultrasound measures of backfat thickness, eye muscle area, and retail cut percentage. Due to age differences among animals at the time of testing, all measures must be adjusted to make them almost equal as points on an individual growth curve. Linear adjustment is the best choice to position measures of traits on straight lines derived from curvilinear growth curves. However, the adjustment method would differ depending on the age 
interval around the test (Bourdon and Brinks, 1986; Wood et al., 1990; Boggess et al., 1991; Kriese et al., 1991; Rossi et al., 1992; Hamlin et al., 1995; Emenheiser et al., 2010) or changes in trait specific variation. Another consideration for an adjustment method is the heterogeneity of variances (Nakaoka et al., 2007). The objective of this study was to investigate the effect of a linear age adjustment on the genetic parameters estimated for days to $90 \mathrm{~kg}$ body weight and ultrasound measures of backfat thickness, eye muscle area, and retail cut percentage in seedstock pig populations in Korea.

\section{MATERIALS AND METHODS}

\section{Performance testing}

Performance records were collected from purebred pig farms. Breeds of purebred pigs included in the study were Landrace, Yorkshire, and Duroc; of these, Landrace and Yorkshire pigs were regarded as the maternal lines, as Duroc boars are used as terminal sires in the three-way crossbreeding system in Korea. A minimum of four pigs per litter were selected for testing after weaning. Body weights were measured once in each pig's lifetime at the time of performance testing without any previous measurement from birth. Therefore, as suggested by Boggess et al. (1991), and assuming an equal birth weight of $1 \mathrm{~kg}$, the number of days to $90 \mathrm{~kg}$ body weight (DAYS90) was calculated according to the Korean Swine Performance Recording Standards (KSPRS), adjusted from birth to the time of testing. The equation used to calculate DAYS90 was:

$$
\text { DAYS90 }=\mathrm{AGE}_{t}+\frac{\left(90 \mathrm{~kg}-\mathrm{BWT}_{t}\right) \times\left(\mathrm{AGE}_{t}-38\right)}{\mathrm{BWT}_{t}},
$$

where, $\mathrm{AGE}_{t}$ and $\mathrm{BWT}_{t}$ are the age of the animal (AGE, day) and body weight $(\mathrm{BW}, \mathrm{kg})$ at the test day, respectively.

At the time of performance testing, ultrasound scanning of the back was conducted with amplitude mode (A-mode) scanners. Backfat thicknesses (BF) on the shoulder (fourth thoracic vertebra), mid-back (last thoracic vertebra), and loin (last lumbar vertebra) were averaged. Eye muscle area (EMA) was estimated by A-mode ultrasound scanning at 5 $\mathrm{cm}$ ventral to the dorsal point of the last thoracic vertebra. The mean of three BF measurements was adjusted for body weight $(\mathrm{ABF})$ using the following equation suggested by KSPRS:

$$
\mathrm{ABF}=\mathrm{BF}_{t}+\frac{\left(90 \mathrm{~kg}-\mathrm{BWT}_{t}\right) \times \mathrm{BF}_{t}}{\mathrm{BWT}_{t}-11.34},
$$

where, $\mathrm{BF}_{t}$ and $\mathrm{BWT}_{t}$ are the average $\mathrm{BF}(\mathrm{mm})$ scanned and $\mathrm{BW}(\mathrm{kg})$ measured at the test day, respectively.

The value of EMA estimated by the A-mode ultrasound scanner was adjusted for body weight (AEMA) on test day using the formula:

$$
\mathrm{AEMA}=\mathrm{EMA}_{t}+\frac{\left(90 \mathrm{~kg}-\mathrm{BWT}_{t}\right) \times \mathrm{EMA}_{t}}{\mathrm{BWT}_{t}+70.31},
$$

where, $\mathrm{EMA}_{t}$ and $\mathrm{BWT}_{t}$ are the average $\mathrm{EMA}\left(\mathrm{cm}^{2}\right)$ scanned and BW $(\mathrm{kg})$ measured at the test, respectively.

Retail cut percentage (RCP) was estimated from the Amode ultrasound scan and was adjusted for body weight (ARCP) on test day using the additive adjustment coefficients in Table 1. Body weight greater than $120 \mathrm{~kg}$ was considered the same as $120 \mathrm{~kg}$ and the same adjustment coefficient $(+2.5 \%)$ was used.

\section{Statistical models}

The analyses of growth performance (DAYS90) and all ultrasound scanned measurements were performed using three multi-trait animal models. Model I included DAYS90 and ultrasound traits without adjustments, whereas model II and III accounted DAYS90 and pre-adjusted ultrasound traits. Fixed factors were sex $(S E X)$ and contemporary group ( $C G$; herd-year-month of birth) of the animal for all traits among the three models. However, an additional linear covariate of final weight on the ultrasound traits was fitted only with model I and II. Variance and covariance components were estimated using REML based REMLF90 software package (Misztal, 2002). The following statistical models were used for the purposes of comparison with the studied traits.

$$
\begin{aligned}
& \text { Model I: } \\
& \text { DAYS90 }=S E X+C G+u+e \\
& (\mathrm{BF}, \mathrm{EMA}, \mathrm{RCP})=S E X+C G+\beta_{l}(\text { finwt })+u+e
\end{aligned}
$$

$$
\begin{aligned}
& \text { Model II: } \\
& \text { DAYS90 }=S E X+C G+u+e
\end{aligned}
$$

Table 1. Adjustment coefficients for retail cut percentage estimated from ultrasound scanner

\begin{tabular}{lc}
\hline $\begin{array}{c}\text { Body weight } \\
\text { at the test }(\mathrm{kg})\end{array}$ & $\begin{array}{c}\text { Additive adjustment coefficient } \\
(\%)\end{array}$ \\
\hline$>70$ and $\leq 75$ & -2.0 \\
$>75$ and $\leq 80$ & -1.5 \\
$>80$ and $\leq 85$ & -1.0 \\
$>85$ and $\leq 90$ & -0.5 \\
$>90$ and $\leq 95$ & 0 \\
$>95$ and $\leq 100$ & 0.5 \\
$>100$ and $\leq 105$ & 1.0 \\
$>105$ and $\leq 110$ & 1.5 \\
$>110$ and $\leq 115$ & 2.0 \\
$>115$ and $\leq 120$ & 2.5 \\
\hline
\end{tabular}


$(\mathrm{ABF}, \mathrm{AEMA}, \mathrm{ARCP})=S E X+C G+\beta_{1}($ finwt $)+u+e$

Model III:

$($ DAYS90, ABF, AEMA, ARCP $)=S E X+C G+u+e$

where, DAYS90 is the days to $90 \mathrm{~kg}$ body weight; ABF, AEMA, and (A)RCP are the (pre-adjusted) mean backfat thickness, eye-muscle area and retail-cut percentages from ultrasound measures, respectively; $C G$ is the contemporary group effect of farm-year-month of birth; SEX is the sex category of the pig (gilt or boar); finwt is the final body weight at the end day of performance testing; and, $\beta_{1}, u$, and $e$ are the linear regression coefficient, the breeding value of the animal, and the environmental effect, respectively.

In matrix notation, the mixed model equation for multitrait analysis was:

$$
\mathrm{y}=\mathrm{Xb}+\mathrm{Zu}+\mathrm{e}
$$

where, $\mathrm{y}$ is the vector of observations, $\mathrm{b}$ is the vector of fixed effects and covariates, $u$ is the vector of additive genetic random effect, $\mathrm{e}$ is the vector of random residual effects, and $\mathrm{X}$ and $\mathrm{Z}$ are known design matrices relating observations to the fixed and random effects $b$ and $u$, respectively. The assumed (co)variance matrices for random and residual effects were $\operatorname{Var}(\mathrm{u})=\mathrm{G}_{\mathrm{o}} \otimes \mathrm{A}$ and $\operatorname{Var}(\mathrm{e})=\mathrm{R}_{\mathrm{o}}$ $\otimes I$, where $G_{0}, A, R_{0}$, and I were the additive genetic (co)variance matrix between traits, the numerator relationship matrix, the residual (co)variance matrix between traits, and the identity matrix, respectively.

The covariance between genetic and environmental effects ( $u$ and e) was assumed to be zero. Heritability and genetic correlations estimates were obtained from the ratios of estimated (co)variance components.

The pedigree and performance data by breed are summarized in Table 2. Least squares means of the traits (data not shown) were very similar to an earlier study by Choi et al. (2013), as data size in this study varied only slightly due to outlier controls. The traits in this study, such as DAYS90, ABF, EMA, and RCP, are equivalent to DAYS90, BF, EMA, and RCP in the previous study, respectively.

\section{RESULTS AND DISCUSSION}

Table 2 shows the data structure and average inbreeding coefficients for the three breeds in the study. The numbers of Duroc boars and gilts for testing were somewhat closer compared to the numbers of boars and gilts in the Landrace and Yorkshire populations, which varied greatly. It may be a Landrace or Yorkshire farmer's preference to test female pigs and keep more females after completing performance testing and cull males after selecting for sires early. The inbreeding coefficient was lowest $(3.4281 \%)$ in Yorkshire pigs.

The summary statistics of each trait used in this study are shown in Table 3. Generally, boars of all three breeds grew quicker than gilts and reached $90 \mathrm{~kg}$ body weight (DAYS90) earlier than gilts. Duroc gilts reached $90 \mathrm{~kg}$ body weight at a younger age than Landrace or Yorkshire gilts. Duroc boars had greater average daily gain (ADG) than did Landrace or Yorkshire boars, but the DAYS90 values for the three breed boars were similar, suggesting different points on each breed's growth curve. Considering each sex separately, the backfat thickness ultrasound data showed that mean BF by breed tended to be slightly thicker as ADG increased. However, the pre-adjusted average backfat (ABF) by breed tended to be thinner, even if the differences were small, as ADG increased in each sex category. EMA and RCP did not follow the pattern of association with DAYS90 as seen for BF. The linear adjustments decreased backfat thickness and eye muscle area in all three breeds on ultrasound, which increased the adjusted retail-cut percentage. We did not compare the mean statistics by breed directly because each breed was raised under different environmental conditions, making direct comparisons inappropriate.

Heritability estimates of the traits $\left(\mathrm{h}^{2}\right)$ (Table 4$)$ showed that DAYS90 and the pork yield predictor traits, BF and RCP, estimated from ultrasound were all moderately to highly heritable ( 0.34 to 0.46$)$. However, as defined by ultrasound data, EMA was minimally heritable, regardless of model ( 0.20 to 0.25 for EMA or AEMA). The heritability estimates of the traits were similar regardless of breed and model. The models varied in the degree of adjustment for body weight at the time of performance testing. The model I

Table 2. Pedigree and performance data structure by breeds

\begin{tabular}{|c|c|c|c|c|c|c|c|}
\hline \multirow{2}{*}{ Breed } & \multirow{2}{*}{$\begin{array}{l}\text { Total no. trait } \\
\text { records }\end{array}$} & \multirow{2}{*}{$\begin{array}{l}\text { No. inbred } \\
\text { animals }\end{array}$} & \multirow{2}{*}{$\begin{array}{l}\text { Average inbreeding } \\
\text { coefficient }(\%)\end{array}$} & \multicolumn{4}{|c|}{ No. levels } \\
\hline & & & & Animal & & & Contemporary group \\
\hline \multirow[t]{2}{*}{ Landrace } & 101,820 & 62,362 & 4.7431 & 112,741 & Boar & 24,970 & 2,316 \\
\hline & & & & & Gilt & 76,752 & \\
\hline \multirow[t]{2}{*}{ Yorkshire } & 281,411 & 169,634 & 3.4281 & 302,313 & Boar & 42,332 & 2,985 \\
\hline & & & & & Gilt & 238,538 & \\
\hline \multirow[t]{2}{*}{ Duroc } & 78,068 & 45,290 & 4.0588 & 86,794 & Boar & 47,230 & 2,104 \\
\hline & & & & & Gilt & 30,637 & \\
\hline
\end{tabular}


Table 3. Summary statistics on the performance records by breeds

\begin{tabular}{|c|c|c|c|c|c|c|c|c|c|c|c|}
\hline \multirow[b]{2}{*}{ Breed } & \multirow[b]{2}{*}{ Sex } & \multirow[b]{2}{*}{ Item } & \multicolumn{9}{|c|}{ Trait } \\
\hline & & & Age & $\begin{array}{l}\text { DAYS90 } \\
\text { (d) }\end{array}$ & $\begin{array}{l}\text { ADG } \\
(\mathrm{g})\end{array}$ & $\begin{array}{c}\mathrm{BF} \\
(\mathrm{mm})\end{array}$ & $\begin{array}{l}\text { EMA } \\
\left(\mathrm{cm}^{2}\right)\end{array}$ & $\begin{array}{l}\mathrm{RCP} \\
(\%)\end{array}$ & $\begin{array}{l}\mathrm{ABF} \\
(\mathrm{mm})\end{array}$ & $\begin{array}{l}\text { AEMA } \\
\left(\mathrm{cm}^{2}\right)\end{array}$ & $\begin{array}{c}\text { ARCP } \\
(\%)\end{array}$ \\
\hline \multirow[t]{6}{*}{ Landrace } & Gilt & No. & 76,809 & 72,820 & 73,098 & 70,641 & 75,343 & 70,182 & 67,050 & 71,734 & 66,784 \\
\hline & & Mean & 161.73 & 150.38 & 607.00 & 14.25 & 47.49 & 57.24 & 12.97 & 45.40 & 57.82 \\
\hline & & $\mathrm{SD}$ & 16.92 & 11.09 & 56.75 & 3.24 & 6.09 & 4.02 & 2.49 & 5.97 & 3.94 \\
\hline & Boar & No. & 25,011 & 23,973 & 23,657 & 23,280 & 24,550 & 22,679 & 21,821 & 22,996 & 21,283 \\
\hline & & Mean & 158.76 & 144.14 & 639.81 & 13.50 & 47.10 & 57.62 & 11.69 & 43.90 & 58.65 \\
\hline & & $\mathrm{SD}$ & 14.78 & 10.66 & 58.65 & 2.98 & 5.80 & 3.66 & 2.19 & 5.44 & 3.54 \\
\hline \multirow[t]{6}{*}{ Yorkshire } & Gilt & No. & 239,011 & 225,318 & 225,247 & 230,751 & 235,542 & 223,247 & 214,804 & 219,729 & 208,350 \\
\hline & & Mean & 159.25 & 152.09 & 596.05 & 14.56 & 47.16 & 57.49 & 13.81 & 45.87 & 57.78 \\
\hline & & SD & 16.29 & 11.18 & 55.64 & 3.13 & 5.62 & 3.36 & 2.81 & 5.43 & 3.34 \\
\hline & Boar & No. & 42,398 & 40,399 & 39,892 & 40,288 & 41,779 & 38,581 & 37,412 & 38,828 & 35,861 \\
\hline & & Mean & 158.56 & 144.77 & 635.60 & 13.63 & 46.79 & 57.90 & 11.90 & 43.79 & 58.87 \\
\hline & & SD & 15.48 & 10.72 & 59.06 & 2.97 & 5.46 & 3.37 & 2.25 & 5.16 & 3.22 \\
\hline \multirow[t]{6}{*}{ Duroc } & Gilt & No. & 30,685 & 29,586 & 29,583 & 26,145 & 28,459 & 23,203 & 24,833 & 27,165 & 22,063 \\
\hline & & Mean & 160.31 & 147.24 & 624.74 & 15.08 & 45.64 & 56.78 & 13.33 & 42.83 & 57.63 \\
\hline & & SD & 15.85 & 10.98 & 56.35 & 3.10 & 6.73 & 3.54 & 2.46 & 6.26 & 3.45 \\
\hline & Boar & No. & 47,383 & 44,579 & 44,214 & 41,359 & 45,020 & 36,470 & 37,841 & 41,416 & 33,253 \\
\hline & & Mean & 160.24 & 143.75 & 645.04 & 14.00 & 45.03 & 57.82 & 11.83 & 41.31 & 59.07 \\
\hline & & SD & 16.65 & 11.14 & 59.73 & 2.76 & 6.54 & 2.99 & 2.05 & 5.89 & 2.91 \\
\hline
\end{tabular}

DAYS90, days to $90 \mathrm{~kg}$ body weight; ADG, average daily gain; BF, backfat thickness; EMA, eye muscle area; RCP, retail cut percentages; ABF, preadjusted BF; AEMA, pre-adjusted EMA; ARCP, pre-adjusted RCP; SD, standard deviation.

ultrasound data were adjusted by linear regression on finwt at the time of performance testing. Model II used ultrasound data pre-adjusted for final weight and were regressed on final body weight. However, final body weight was not regressed in pre-adjusting the ultrasound data using model III. The estimates determined in our study were closer to the values in the literature (Chen et al., 2002; Noguera et al., 2002; Kim et al., 2004; Arrango et al., 2005; Choi et al., 2013). Hicks et al. (1999) reported much higher heritability estimates (0.43 for ADG and 0.69 for BF) in a Japanese Large White population. Suzuki et al. (2006) also reported higher heritability estimates in Duroc ( 0.51 for ADG, 0.48 for EMA, and 0.73 for $\mathrm{BF}$ ) when they measured pigs at a body weight of $105 \mathrm{~kg}$ and used B-mode ultrasound instead of the A-mode used in our study. Li and Kennedy (1994) also reported lower $\mathrm{h}^{2}$ estimates for days to $100 \mathrm{~kg}$ body weight (0.26 to 0.32$)$ in Canadian populations, but they found slightly higher $h^{2}$ estimates for back fat thickness (0.50 to 0.55$)$.

Backfat thickness from model I (Tables 4 and 5), which used the ultrasound data without pre-adjusting for age and final weight on test day as linear covariates, showed moderate and negative genetic and environmental correlations with DAYS90. The genetic and environmental correlations between pre-adjusted BF and DAYS90 were low but negative in all three breeds. Kim et al. (2004) studied a subpopulation (a Korean cooperative farm) of the present study population and showed all negative genetic and phenotypic correlations between these two traits from the same breeds (Duroc, Landrace, and Large White). Their estimates were similar to the estimates of $\mathrm{Li}$ and Kennedy (1994) in Canadian populations. Chen et al. (2002) reported that the genetic and phenotypic correlations between days to $113.5 \mathrm{~kg}$ and backfat thickness were all negative but close to zero. Their estimates of the genetic correlations were very consistent with those found in the present study (model II). The genetic correlations between BF and EMA were mostly low and negative for model I $(-0.15$ to -0.19$)$. However, the genetic correlations between these traits were moderate and negative using models II $(-0.35$ to -0.38$)$ and III $(-0.27$ to -0.33$)$ after pre-adjustment (ABF and AEMA). These correlation estimates also agreed with estimates reported by Chen et al. (2002) and Choi et al. (2013). The environmental correlations between BF and EMA were near zero to low positive (Table 5) in model I, and models II and III obtained similar correlations, close to zero but mostly negative. The genetic correlations between EMA and DAYS90 were negative among breeds i.e., -0.16 (Duroc) to -0.26 (Landrace). However, these correlations became positive ( 0.27 to 0.30 ) when the trait measures were pre-adjusted (AEMA and DAYS90) in model III, or decreased to near zero $(0.008$ to 0.11$)$ in model II, which included final weight as covariate. The genetic correlations between these two traits reported by Chen et al. (2002) were also low but positive. Small positive ( 0.20 to 0.28$)$ genetic correlations were found between DAYS90 and RCP in the 
Table 4. Genetic variances (diagonals), covariances (above the diagonals), heritability estimates $\left(\mathrm{h}^{2}\right)$, and genetic correlation coefficients (below the diagonals) of growth and ultrasound measures by breeds

\begin{tabular}{|c|c|c|c|c|c|c|c|c|c|c|c|c|c|}
\hline \multirow[b]{2}{*}{ Breed } & \multirow[b]{2}{*}{ Trait } & \multicolumn{4}{|c|}{ Model I } & \multicolumn{4}{|c|}{ Model II } & \multicolumn{4}{|c|}{ Model III } \\
\hline & & $\begin{array}{l}\text { DAYS90 } \\
\text { (d) }\end{array}$ & $\begin{array}{c}\mathrm{BF} \\
(\mathrm{mm})\end{array}$ & $\begin{array}{l}\text { EMA } \\
\left(\mathrm{cm}^{2}\right)\end{array}$ & $\begin{array}{l}\mathrm{RCP} \\
(\%)\end{array}$ & $\begin{array}{l}\text { DAYS90 } \\
\text { (d) }\end{array}$ & $\begin{array}{l}\text { (A)BF } \\
(\mathrm{mm})\end{array}$ & $\begin{array}{c}\text { (A)EMA } \\
\left(\mathrm{cm}^{2}\right)\end{array}$ & $\begin{array}{c}\text { (A)RCP } \\
(\%)\end{array}$ & $\begin{array}{l}\text { DAYS90 } \\
\text { (d) }\end{array}$ & $\begin{array}{l}\text { (A)BF } \\
(\mathrm{mm})\end{array}$ & $\begin{array}{c}\text { (A)EMA } \\
\left(\mathrm{cm}^{2}\right)\end{array}$ & $\begin{array}{c}\text { (A)RCP } \\
(\%)\end{array}$ \\
\hline \multirow[t]{5}{*}{ Landrace } & DAYS90 & 41.04 & -4.02 & -3.85 & 2.57 & 39.55 & -0.40 & 0.10 & 0.45 & 39.71 & 0.45 & 3.76 & -0.07 \\
\hline & (A)BF & -0.34 & 3.35 & -0.62 & -2.85 & -0.04 & 2.16 & -1.06 & -2.20 & 0.05 & 2.18 & -0.94 & -2.22 \\
\hline & (A)EMA & -0.26 & -0.15 & 5.29 & 1.41 & 0.01 & -0.35 & 4.30 & 1.68 & 0.27 & -0.29 & 4.91 & 1.59 \\
\hline & (A)RCP & 0.23 & -0.91 & 0.35 & 2.97 & 0.04 & -0.91 & 0.49 & 2.72 & -0.01 & -0.91 & 0.43 & 2.73 \\
\hline & $\begin{array}{l}\mathrm{h}^{2} \\
(\mathrm{SE})^{\mathrm{a}}\end{array}$ & $\begin{array}{c}0.42 \\
(0.01)\end{array}$ & $\begin{array}{c}0.43 \\
(0.01)\end{array}$ & $\begin{array}{c}0.22 \\
(0.01)\end{array}$ & $\begin{array}{c}0.45 \\
(0.01)\end{array}$ & $\begin{array}{c}0.41 \\
(0.01)\end{array}$ & $\begin{array}{c}0.44 \\
(0.01)\end{array}$ & $\begin{array}{c}0.22 \\
(0.01)\end{array}$ & $\begin{array}{c}0.46 \\
(0.01)\end{array}$ & $\begin{array}{c}0.41 \\
(0.01)\end{array}$ & $\begin{array}{c}0.44 \\
(0.01)\end{array}$ & $\begin{array}{c}0.23 \\
(0.01)\end{array}$ & $\begin{array}{c}0.46 \\
(0.01)\end{array}$ \\
\hline \multirow[t]{5}{*}{ Yorkshire } & DAYS90 & 37.00 & -4.12 & -2.66 & 3.02 & 35.71 & -0.95 & 1.38 & 1.29 & 35.70 & 0.12 & 4.04 & 0.71 \\
\hline & (A)BF & -0.38 & 3.21 & -0.77 & -2.95 & -0.11 & 2.28 & -1.22 & -2.38 & 0.01 & 2.27 & -1.13 & -2.36 \\
\hline & (A)EMA & -0.19 & -0.19 & 5.15 & 1.55 & 0.11 & -0.38 & 4.58 & 1.92 & 0.30 & -0.33 & 5.15 & 1.91 \\
\hline & (A)RCP & 0.28 & -0.93 & 0.38 & 3.14 & 0.13 & -0.93 & 0.53 & 2.90 & 0.07 & -0.92 & 0.50 & 2.88 \\
\hline & $\begin{array}{l}\mathrm{h}^{2} \\
(\mathrm{SE})^{\mathrm{a}}\end{array}$ & $\begin{array}{c}0.38 \\
(0.01)\end{array}$ & $\begin{array}{c}0.41 \\
(0.01)\end{array}$ & $\begin{array}{c}0.22 \\
(0.01)\end{array}$ & $\begin{array}{c}0.43 \\
(0.01)\end{array}$ & $\begin{array}{c}0.37 \\
(0.01)\end{array}$ & $\begin{array}{c}0.41 \\
(0.01)\end{array}$ & $\begin{array}{c}0.23 \\
(0.01)\end{array}$ & $\begin{array}{c}0.43 \\
(0.01)\end{array}$ & $\begin{array}{c}0.37 \\
(0.01)\end{array}$ & $\begin{array}{c}0.41 \\
(0.01)\end{array}$ & $\begin{array}{c}0.25 \\
(0.01)\end{array}$ & $\begin{array}{c}0.43 \\
(0.01)\end{array}$ \\
\hline \multirow[t]{5}{*}{ Duroc } & DAYS90 & 34.74 & -2.43 & -1.96 & 1.78 & 33.52 & -0.33 & 0.55 & 0.71 & 33.65 & 0.49 & 3.10 & 0.12 \\
\hline & (A)BF & -0.29 & 2.00 & -0.45 & -1.85 & -0.05 & 1.16 & -0.76 & -1.39 & 0.08 & 1.20 & -0.58 & -1.42 \\
\hline & (A)EMA & -0.16 & -0.15 & 4.25 & 1.36 & 0.05 & -0.38 & 3.40 & 1.56 & 0.27 & -0.27 & 3.98 & 1.41 \\
\hline & (A)RCP & 0.20 & -0.87 & 0.44 & 2.24 & 0.09 & -0.89 & 0.58 & 2.11 & 0.01 & -0.89 & 0.48 & 2.14 \\
\hline & $\begin{array}{l}\mathrm{h}^{2} \\
(\mathrm{SE})^{\mathrm{a}}\end{array}$ & $\begin{array}{c}0.37 \\
(0.01)\end{array}$ & $\begin{array}{c}0.34 \\
(0.01)\end{array}$ & $\begin{array}{c}0.20 \\
(0.01)\end{array}$ & $\begin{array}{c}0.39 \\
(0.01)\end{array}$ & $\begin{array}{c}0.36 \\
(0.01)\end{array}$ & $\begin{array}{c}0.35 \\
(0.01)\end{array}$ & $\begin{array}{c}0.20 \\
(0.01)\end{array}$ & $\begin{array}{c}0.41 \\
(0.01)\end{array}$ & $\begin{array}{c}0.36 \\
(0.01)\end{array}$ & $\begin{array}{c}0.35 \\
(0.01)\end{array}$ & $\begin{array}{c}0.22 \\
(0.01)\end{array}$ & $\begin{array}{c}0.41 \\
(0.01)\end{array}$ \\
\hline
\end{tabular}

DAYS90, days to $90 \mathrm{~kg}$ body weight; BF, backfat thickness; EMA, eye muscle area; RCP, retail cut percentages; ABF, pre-adjusted BF; AEMA, preadjusted EMA; ARCP, pre-adjusted RCP.

${ }^{a}$ SE, approximate standard errors estimated using ASREML 3.0 software package (Gilmour et al., 2009).

three pig breeds. These relationships became negligible models. The genetic correlations between EMA and RCP when the adjusted RCP (ARCP) was used in models II were moderate and positive (0.35 to 0.44), and the and III $(-0.006$ to 0.13$)$. The magnitude and pattern of correlations became slightly stronger in models II and III. A change in the estimates across models were similar for the similar pattern was found in the environmental correlations genetic and environmental correlations between DAYS90 between these two traits. and RCP. The genetic correlations between BF and RCP were high and negative $(-0.87$ to -0.93$)$ and were not affected by pre-adjustment or fitting covariates in the models. The environmental correlations between $\mathrm{BF}$ and RCP were moderate and negative, and invariant to the
Korean swine performance testing ends at an earlier age $(90 \mathrm{~kg})$ compared with the STAGES (Swine Testing and Genetic Evaluation System) in the USA (NSIF, 1997), which ends at about $110 \mathrm{~kg}$ body weight, or with the Japanese system, which ends at about $105 \mathrm{~kg}$ body weight

Table 5. Environmental variances (diagonals), covariances (above the diagonals), heritability estimates $\left(\mathrm{h}^{2}\right)$ and genetic correlation coefficients (below the diagonals) of growth and ultrasound measures by breeds

\begin{tabular}{|c|c|c|c|c|c|c|c|c|c|c|c|c|c|}
\hline \multirow[b]{2}{*}{ Breed } & \multirow[b]{2}{*}{ Trait } & \multicolumn{4}{|c|}{ Model I } & \multicolumn{4}{|c|}{ Model II } & \multicolumn{4}{|c|}{ Model III } \\
\hline & & $\begin{array}{l}\text { DAYS90 } \\
\text { (d) }\end{array}$ & $\begin{array}{c}\mathrm{BF} \\
(\mathrm{mm})\end{array}$ & $\begin{array}{l}\text { EMA } \\
\left(\mathrm{cm}^{2}\right)\end{array}$ & $\begin{array}{l}\text { RCP } \\
(\%)\end{array}$ & $\begin{array}{l}\text { DAYS90 } \\
\text { (d) }\end{array}$ & $\begin{array}{l}\text { ABF } \\
(\mathrm{mm})\end{array}$ & $\begin{array}{l}\text { AEMA } \\
\left(\mathrm{cm}^{2}\right)\end{array}$ & $\begin{array}{c}\text { ARCP } \\
(\%)\end{array}$ & $\begin{array}{l}\text { DAYS90 } \\
\text { (d) }\end{array}$ & $\begin{array}{l}\mathrm{ABF} \\
(\mathrm{mm})\end{array}$ & $\begin{array}{l}\text { AEMA } \\
\left(\mathrm{cm}^{2}\right)\end{array}$ & $\begin{array}{c}\text { ARCP } \\
(\%)\end{array}$ \\
\hline \multirow[t]{4}{*}{ Landrace } & DAYS90 & 56.73 & -5.67 & -6.50 & 3.81 & 57.15 & -0.22 & -0.93 & 0.39 & 57.09 & 1.16 & 4.62 & -0.43 \\
\hline & (A)BF & -0.36 & 4.49 & 0.50 & -2.16 & -0.02 & 2.73 & -0.48 & -1.32 & 0.09 & 2.78 & -0.29 & -1.34 \\
\hline & (A)EMA & -0.20 & 0.05 & 18.44 & 1.81 & -0.03 & -0.08 & 15.29 & 2.30 & 0.15 & -0.04 & 16.07 & 2.24 \\
\hline & (A)RCP & 0.26 & -0.53 & 0.22 & 3.68 & 0.03 & -0.45 & 0.33 & 3.22 & -0.03 & -0.45 & 0.31 & 3.22 \\
\hline \multirow[t]{4}{*}{ Yorkshire } & DAYS 90 & 60.94 & -6.01 & -7.25 & 4.10 & 61.25 & -0.95 & -0.86 & 1.15 & 61.27 & 0.86 & 3.50 & 1.00 \\
\hline & (A)BF & -0.36 & 4.69 & 0.52 & -2.37 & -0.07 & 3.23 & -0.64 & -1.62 & 0.06 & 3.29 & -0.47 & -1.63 \\
\hline & (A)EMA & -0.22 & 0.06 & 17.94 & 2.19 & -0.03 & -0.09 & 15.07 & 2.80 & 0.11 & -0.07 & 15.53 & 2.75 \\
\hline & (A)RCP & 0.26 & -0.53 & 0.25 & 4.20 & 0.08 & -0.46 & 0.37 & 3.79 & 0.01 & -0.46 & 0.36 & 3.79 \\
\hline \multirow[t]{4}{*}{ Duroc } & DAYS90 & 58.37 & -5.28 & -6.12 & 3.76 & 58.80 & -0.57 & -0.91 & 1.33 & 58.74 & 1.32 & 4.43 & -0.24 \\
\hline & (A)BF & -0.35 & 3.87 & 0.92 & -1.72 & -0.05 & 2.14 & -0.11 & -1.02 & 0.12 & 2.24 & 0.21 & -1.06 \\
\hline & (A)EMA & -0.19 & 0.11 & 16.97 & 1.76 & -0.03 & -0.02 & 13.47 & 2.10 & 0.15 & 0.04 & 14.28 & 1.91 \\
\hline & (A)RCP & 0.26 & -0.47 & 0.23 & 3.47 & 0.10 & -0.40 & 0.33 & 3.02 & -0.02 & -0.41 & 0.29 & 3.02 \\
\hline
\end{tabular}

DAYS90, days to $90 \mathrm{~kg}$ body weight; BF, backfat thickness; EMA, eye muscle area; RCP, retail cut percentages; ABF, pre-adjusted backfat thickness; AEMA, pre-adjusted eye muscle area; ARCP, pre-adjusted retail cut percentages. 
(Suzuki et al., 2006). The ultrasound scanned body measurements (BF, EMA, and RCP) were pre-adjusted with formulas (ABF and AEMA) and additive adjustment factors (ARCP with adjustment factors shown in Table 1), similar to the STAGES process, with some modifications. However, body compositional changes may be different from body weight changes depending on the point on the growth curve at which the animals were assigned to testing (Emenheiser et al., 2010) or depending on different body growth patterns by breed, which may have diverged due to different breeding objectives. In our study, the genetic and environmental (co)variances of the unadjusted traits (model I) from ultrasound scans were compared with those of adjusted traits (model III). We added another model (model II) that further adjusted for extra variation due to body weight growth (finwt) for the pre-adjusted growth and ultrasound scanned measures (DAYS90, ABF, AEMA, and ARCP).

DAYS90 was negatively or positively correlated with BF, EMA or RCP both genetically and environmentally before pre-adjustment. However, those correlation coefficients were negligible in model II. When only the preadjustments were applied, the genetic and environmental correlations between DAYS90 and backfat thickness (BF to $\mathrm{ABF}$ ) or between DAYS90 and retail cut percentage (RCP to ARCP) were close to zero. The genetic and environmental correlation coefficients between DAYS90 and eye muscle area shifted from negative (model I) to positive (model III).

The genetic correlations between BF and EMA were negative, which became even greater (more negative) after pre-adjustments were applied (models II and III). The genetic and environmental correlations between $\mathrm{BF}$ and RCP were large and negative ( -0.9 genetically and -0.4 environmentally), and pre-adjustments ( $\mathrm{ABF}$ and $\mathrm{ARCP}$ ) changed these correlation coefficients. The genetic and environmental correlations between EMA and RCP were positive, and the coefficients became greater when preadjustments were adopted in models II and III. These changing patterns across models were similar in all breeds. The parameters estimated from model III for DAYS90, ABF, and AEMA were similar to previous reports.

Among the models studied, the model II might have encountered an over-fitting through traits adjustments, in which an initial pre-adjustment of trait was followed by an additional covariates adjustment. However, the major reason for these models fit was to verify the preadjustments, if they were favorable to accommodate the body compositional growth variation by individual animal.

Therefore, we conclude that ultrasound data taken at about $90 \mathrm{~kg}$ body weight on test day should be adjusted for body weight growth. We also suggest that the adjustment formula, particularly for BF and EMA should be revised to accommodate extra variation due to different performance testing endpoints associated with differential growth in body composition.

\section{CONFLICT OF INTEREST}

We certify that there is no conflict of interest with any financial organization regarding the material discussed in the manuscript.

\section{ACKNOWLEDGMENTS}

This study was carried out with support of the "Cooperative Research Program for Agriculture Science \& Technology Development (Project title: Research on the National Livestock Resource Evaluation and Breeding System-National swine and chicken breeding strategy development, Project No. PJ008453)", Rural Development Administration, Korea. The authors also acknowledge the significant efforts of the Korea Animal Improvement Association (KAIA) for collecting and managing the pig performance database.

\section{REFERENCES}

Arango, J., I. Misztal, S. Tsuruta, M. Culbertson, and W. Herring. 2005. Threshold-linear estimation of genetic parameters for farrowing mortality, litter size, and test performance of Large White sows. J. Anim. Sci. 83:499-506.

Boggess, M. V., D. E. Wilson, M. F. Rothschild, and D. G. Morrical. 1991. National sheep improvement program: age adjustment of weaning weight. J. Anim. Sci. 69:3190-3201.

Bourdon, R. M. and J. S. Brinks. 1986. Scrotal circumference in yearling Hereford bulls: Adjustment factors, heritabilities and genetic, environmental and phenotypic relationships with growth traits. J. Anim. Sci. 62:958-967.

Chen, P., T. J. Baas, J. W. Mabry, J. C. Dekkers, and K. J. Koehler. 2002. Genetic parameters and trends for lean growth rate and its comvonents in U.S. Yorkshire, Duroc, Hampshire, and Landrace pigs. J. Anim. Sci. 80:2062-2070.

Choi, J. G., C. I. Cho, I. S. Choi, S. S. Lee, T. J. Choi, K. H. Cho, B. H. Park, and Y. H. Choy. 2013. Genetic parameter estimation in seedstock Swine population for growth performances. Asian Australas. J. Anim. Sci. 26:470-475.

Emenheiser, J. C., S. P. Greiner, R. M. Lewis, and D. R. Notter. 2010. Longitudinal changes in ultrasonic measurements of body composition during growth in Suffolk ram lambs and evaluation of alternative adjustment strategies for ultrasonic scan data. J. Anim. Sci. 88:1341-1348.

Gilmour, A. R., B. J. Gogel, B. R. Cullis, and R. Thompson. 2009. ASReml User Guide, Release 3.0. VSN International Ltd, Hemel Hempstead, UK.

Hamlin, K. E., R. D. Green, T. L. Perkins, L. V. Cundiff, and M. F. Miller. 1995. Real-time ultrasonic measurement of fat thickness and longissimus muscle area: I. Description of age 
and weight effects. J. Anim. Sci. 73:1713-1724.

Hicks, C., M. Satoh, K. Ishii, S. Kuroki, T. Fujiwara, and T. Furukawa. 1999. Effect of sex on estimates of genetic parameters for daily gain and ultrasonic backfat thickness in swine. Asian Australas. J. Anim. Sci. 12:677-681.

Kim, J. I., Y. G. Sohn, J. H. Jung, and Y. I. Park. 2004. Genetic parameter estimates for backfat thickness at three different sites and growth rate in swine. Asian Australas. J. Anim. Sci. 17:305-308.

Kriese, L. A., J. K. Bertrand, and L. L. Benyshek. 1991. Age adjustment factors, heritabilities and genetic correlations for scrotal circumference and related growth traits in Hereford and Brangus bulls. J. Anim Sci. 69:478-489.

Li, X. and B. W. Kennedy. 1994. Genetic parameters for growth rate and backfat in Canadian Yorkshire, Landrace, Duroc, and Hampshire pigs. J. Anim. Sci. 72:1450-1454.

Misztal, I. 2002. REMLF90 Mannual. http://nce.ads.uga.edu/ $\sim$ ignacy/numpub/blupf90/docs/remlf90.pdf. Accessed on Jun 15,2014
Nakaoka, H., A. Narita, T. Ibi, Y. Sasae, T. Miyake, T. Yamada, and Y. Sasaki. 2007. Effectiveness of adjusting for heterogeneity of variance in genetic evaluation of Japanese Black cattle. J. Anim. Sci. 85:2429-2436.

Noguera, J. L., L. Varona, D. Babot, and J. Estany. 2002. Multivariate analysis of litter size for multiple parities with production traits in pigs: I. Bayesian variance component estimation. J. Anim. Sci. 80:2540-2547.

NSIF. 1997. Guidelines for Uniform Swine Improvement Programs. USDA, Washington, DC, USA.

Rossi, D. J., D. D. Kress, M. W. Tess, and P. J. Burfening. 1992. Correcting bias from the standard linear adjustment of weaning weight to an age-constant basis for beef calves. J. Anim. Sci. 70:1333-1341.

Suzuki, K., M. Ishida, H. Kadowaki, T. Shibata, H. Uchida, and A. Nishida. 2006. Genetic correlations among fatty acid compositions in different sites of fat tissues, meat production, and meat quality traits in Duroc pigs. J. Anim. Sci. 84:20262034.

Wood, C. M., L. L. Christian, and M. F. Rothschild. 1990. Factors to adjust litter weight of pigs to a standard 21 days of age. J. Anim. Sci. 68:2628-2633. 